\title{
Genotypic prediction of HIV-1 subtype D tropism
}

\author{
Stéphanie Raymond ${ }^{1,2,3^{*}}$, Pierre Delobel ${ }^{1,2,4}$, Marie-Laure Chaix ${ }^{5}$, Michelle Cazabat ${ }^{1,3}$, Stéphanie Encinas ${ }^{1,3}$, \\ Patrick Bruel ${ }^{1,3}$, Karine Sandres-Sauné ${ }^{1,2,3}$, Bruno Marchou ${ }^{4}$, Patrice Massip ${ }^{4}$ and Jacques Izopet ${ }^{1,2,3}$
}

\begin{abstract}
Background: HIV-1 subtype D infections have been associated with rapid disease progression and phenotypic assays have shown that CXCR4-using viruses are very prevalent. Recent studies indicate that the genotypic algorithms used routinely to assess HIV-1 tropism may lack accuracy for non-B subtypes. Little is known about the genotypic determinants of HIV-1 subtype D tropism.

Results: We determined the HIV-1 coreceptor usage for 32 patients infected with subtype D by both a recombinant virus phenotypic entry assay and V3-loop sequencing to determine the correlation between them. The sensitivity of the Geno2pheno10 genotypic algorithm was 75\% and that of the combined 11/25 and net charge rule was 100\% for predicting subtype D CXCR4 usage, but their specificities were poor (54\% and 68\%). We have identified subtype D determinants in the V3 region associated with CXCR4 use and built a new simple genotypic rule for optimizing the genotypic prediction of HIV-1 subtype D tropism. We validated this algorithm using an independent GenBank data set of 67 subtype D V3 sequences of viruses of known phenotype. The subtype D genotypic algorithm was $68 \%$ sensitive and $95 \%$ specific for predicting X4 viruses in this data set, approaching the performance of genotypic prediction of HIV-1 subtype B tropism.

Conclusion: The genotypic determinants of HIV-1 subtype D coreceptor usage are slightly different from those for subtype B viruses. Genotypic predictions based on a subtype D-specific algorithm appear to be preferable for characterizing coreceptor usage in epidemiological and pathophysiological studies.
\end{abstract}

\section{Background}

Human immunodeficiency virus type 1 (HIV-1) enters CD4-expressing cells using one or both of the chemokine receptors CCR5 and CXCR4 [1]. The receptor(s) used by HIV-1 must be identified before a patient is treated with CCR5 antagonists, as these drugs can only be used against R5 viruses alone [2]. Recombinant virus phenotypic entry assays have been widely used to determine HIV-1 tropism [3-5] but genotypic methods based on the V3 sequence could be easier. Several studies indicate that the V3 genotype, combined with bioinformatic algorithms, accurately predicts the phenotype of HIV-1 coreceptor usage for subtype B viruses [6-10]. But the V3-based genotypic algorithms may be unsuitable for predicting the tropism of non-B viruses because they were built using genotype-phenotype correlation data for subtype B viruses [9]. These algorithms can perform differently, as was reported for HIV-1 subtype B $[6,10]$.

\footnotetext{
* Correspondence: raymond.s@chu-toulouse.fr

'INSERM, U1043, Toulouse, F-31300 France

Full list of author information is available at the end of the article
}

The geno2pheno bioinformatic tool accurately predicts subtype C HIV-1 tropism, but is relatively insensitive for predicting CRF02 CXCR4 usage [11,12]. In contrast, the simple rule combining 11/25 and net charge rules accurately predicts HIV-1 tropism for these particular non-B subtypes. The predominant viruses in Uganda and Sudan are subtype D [13]. These subtype D infections are associated with a rapid loss of CD4 cells and disease progression [14-18]. Various phenotypic assays have been used to show that CXCR4-using viruses are very prevalent among subtype D HIV-1 [19-21]. However, little is known about the genotypic determinants of the virus's subtype D tropism [20-23].

This study evaluates the performance of the genotypic algorithms built for subtype B viruses for predicting HIV-1 subtype D tropism. We determined subtype D coreceptor usage with both genotypic and phenotypic assays. The poor concordance between them led us to look for genotypic criteria that could be used to predict the coreceptor usage of subtype D viruses and to define a new genotypic tool for this particular subtype. Lastly,
C Biomed Central

(c) 2011 Raymond et al; licensee BioMed Central Ltd. This is an Open Access article distributed under the terms of the Creative Commons Attribution License (http://creativecommons.org/licenses/by/2.0), which permits unrestricted use, distribution, and reproduction in any medium, provided the original work is properly cited. 
we checked the subtype D genotypic tool against a GenBank data set of subtype D viruses for which both the $\mathrm{V} 3$ sequence and the entry phenotype were known.

\section{Methods}

Study subjects and samples

We studied 32 individuals infected with HIV-1 subtype D recruited at the Department of Infectious Diseases of Toulouse University Hospital, France and at the Department of Virology of Necker-Enfants Malades Hospital, Paris, France. The median age of the patients was 42 years and $46 \%$ were men. The median HIV-1 virus load was $4.91 \log _{10}$ copies/ml (IQR [4.1-5.16]). The median CD4 cell count was 355 cells $/ \mathrm{mm}^{3}$ (IQR [208.7-634]) and the percentage of CD4 cells was $17 \%$ (IQR [1019.5]). All viruses were identified as HIV-1 subtype D by analysis of the env sequence using the NCBI genotyping tool (http://www.ncbi.nlm.nih.gov/projects/genotyping/ formpage.cgi). We confirmed that these viruses belonged to the subtype $\mathrm{D}$ by neighbor-joining phylogenetic analysis of the sequences studied here, together with HIV-1 subtype reference sequences from the Los Alamos National Laboratory (http://www.hiv.lanl.gov/content/ index).

\section{GenBank data set of HIV-1 subtype D viruses}

The V3 sequences of HIV-1 subtype D viruses whose entry phenotype was known were selected from the GenBank database. We selected sequences resulting from bulk sequencing or one sequence per patient in the case of clonal analysis. The entry phenotype of the 67 subtype $\mathrm{D}$ viruses had been determined with the MT2 assay or with the Trofile ${ }^{\circledR}$ assay (Monogram, Biosciences).

\section{Phenotypic characterization of HIV-1 coreceptor usage}

We determined the HIV-1 tropism with the TTT phenotypic assay [3]. Briefly, a fragment encompassing the gp120 and the ectodomain of gp41 was amplified by RT-PCR using HIV-1 RNA isolated from the plasma or by PCR from HIV-1 DNA taken from PBMCs. The PCR products then underwent nested PCR. Two amplifications were performed in parallel on aliquots of each sample; the amplified products were then pooled to prevent sampling bias of the virus population.

The phenotype of HIV-1 coreceptor usage was determined using a recombinant virus entry assay with the pNL43- $\Delta$ env-Luc2 vector. $293 \mathrm{~T}$ cells were co-transfected with NheI-linearized pNL43- $\Delta e n v$-Luc2 vector DNA and the product of the nested PCR obtained from the challenged HIV-1-containing sample. The chimeric recombinant virus particles released into the supernatant were used to infect U87 indicator cells bearing CD4 and either CCR5 or CXCR4. Virus entry was assessed by measuring the luciferase activity in lysed cells (as relative light units; RLU). Minor X4 variants were detected when they accounted for $0.5 \%$ or more of the total population.

\section{Genotypic prediction of HIV-1 coreceptor usage}

The V3 region was directly sequenced from bulk env PCR products in both directions by the dideoxy chaintermination method (BigDye Terminator v3.1; Applied Biosystems, Courtaboeuf, France) on an ABI 3130 DNA sequencer. The two primer pairs used for sequencing have been described [10]. Results were analyzed with Sequencher (Genecodes, Ann Arbor, MI) by an operator blinded to the phenotype. Minority species were detected when the automated sequencer electropherogram showed a second base peak. Multiple alignments were performed with CLUSTALW 1.83, and sequence alignments were manually edited with BioEdit software. Phylogenetic analyses excluded any possibility of sample contamination (data not shown).

We used a combination of criteria from the 11/25 and net charge rules to predict HIV-1 tropism from the V3 genotype [10]. One of the following criteria is required for predicting CXCR4 coreceptor usage: (i) $11 \mathrm{R} / \mathrm{K}$ and/ or $25 \mathrm{~K}$ in V3; (ii) $25 \mathrm{R}$ in V3 and a net charge of $\geq+5$; (iii) a net charge of $\geq+6$. The V3 net charge was calculated by subtracting the number of negatively charged amino acids [D and E] from the number of positively charged ones [K and R]. All possible permutations were assessed when amino acid mixtures were found at some codons of V3. The combination resulting in the highest net charge was used to predict the tropism. We also used the geno2pheno tool (with a false positive rate of $10 \%)$ to predict HIV-1 coreceptor usage. Geno2pheno is available at http://coreceptor.bioinf.mpi-sb.mpg.de/cgibin/coreceptor.pl (September 2010).

\section{Cloning of env PCR products}

The env PCR products from three patients were subjected to clonal analysis using a TOPO-TA cloning kit (Invitrogen). Plasmids DNA containing env inserts were sequenced in the V3 region using the primers previously described [10].

\section{Statistical methods}

The kappa coefficient was measured using STATA SE 9.2 to assess agreement between the genotypic algorithms for HIV-1 tropism prediction and the phenotypic assay. The correlation between two tests is usually considered good when the kappa coefficient is superior to 0.60 with $\mathrm{p}<0.05$.

\section{Nucleotide sequence accession numbers}

The sequences reported here have been given GenBank accession numbers HQ906854-HQ906879. 


\section{Results}

Phenotypic characterization of HIV-1 subtype D viruses

The env products from the plasma sample of 27 of the 32 subtype D-infected patients were successfully amplified by PCR. The phenotype of receptor-mediated entry was then successfully determined for each of these 27 patients. We found 23 virus populations with an R5 phenotype, 2 virus populations with a dual/mixed R5X4 phenotype, and 2 virus populations with a pure X4 phenotype.

Genotypic prediction of subtype D coreceptor usage with algorithms built for subtype $B$ viruses

The V3 region was sequenced from the bulk env PCR products of the viruses from 26 patients (Figure 1a). We thus obtained genotype-phenotype correlations for
26 patients. The combined $11 / 25$ and net charge rule predicted $15 \mathrm{R} 5$ viruses and $11 \mathrm{X} 4$ viruses, but 7 of them were mis-predicted as X4. Geno2pheno10 predicted $13 \mathrm{R} 5$ viruses and $13 \mathrm{X} 4$ viruses (10 were mispredicted as $\mathrm{X} 4$ ). As summarized in Table 1 geno2pheno 10 was $75 \%$ sensitive and $54 \%$ specific and the combined rule was $100 \%$ sensitive and $68 \%$ specific for predicting CXCR4-usage by HIV-1 subtype D. The concordance between the genotypic and phenotypic approaches was $58 \%$ with geno2pheno10 and $73 \%$ with the combined rule (Table 1).

\section{Genotypic determinants predicting CXCR4 use by HIV-1 subtype $D$ viruses}

We looked for V3 genotypic determinants known to be associated with CXCR4 usage by subtype B viruses, as

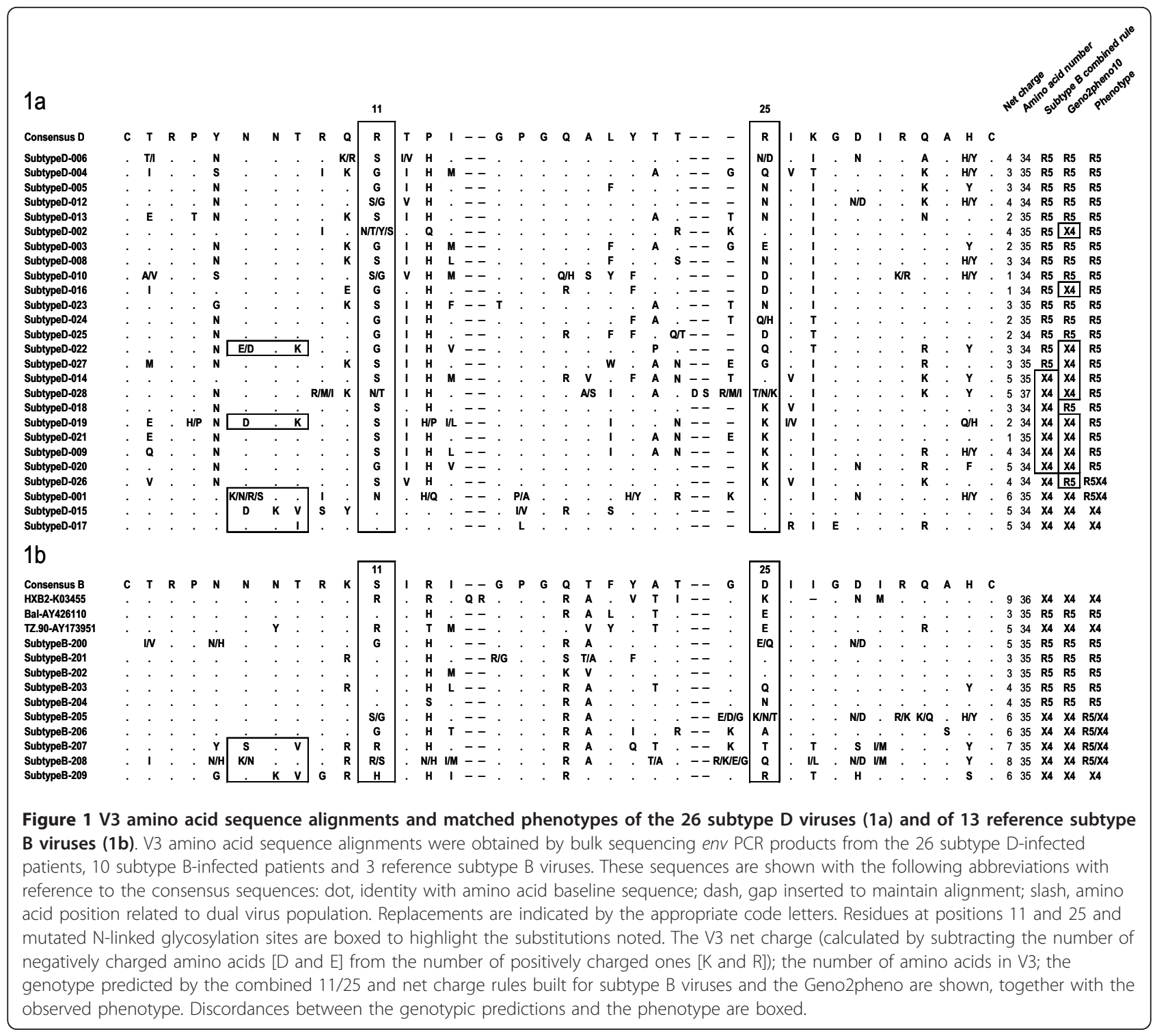


Table 1 Genotypic prediction of HIV-1 subtype D tropism compared to the TTT phenotypic assay

\begin{tabular}{|c|c|c|c|c|c|c|}
\hline \multirow[b]{2}{*}{ Genotypic tool } & & \multicolumn{2}{|c|}{ TTT } & \multirow[t]{2}{*}{ Concordance } & \multicolumn{2}{|c|}{ Genotypic Prediction } \\
\hline & & R5 & $\mathrm{R} 5 \mathrm{X} 4 / \mathrm{X} 4$ & & $\operatorname{Sen}^{\mathrm{a}}$ & $\mathrm{Spe}^{\mathrm{b}}$ \\
\hline \multirow[t]{2}{*}{ Geno2pheno10 } & R5 & 12 & 1 & $58 \%$ & $75 \%$ & $54 \%$ \\
\hline & $\mathrm{X} 4$ & 10 & 3 & $\kappa=0.15(p=0.14)$ & & \\
\hline \multirow[t]{2}{*}{ Combined $11 / 25$ and net charge rules } & R5 & 15 & 0 & $73 \%$ & $100 \%$ & $68 \%$ \\
\hline & $\mathrm{X} 4$ & 7 & 4 & $\kappa=0.40(p<0.01)$ & & \\
\hline
\end{tabular}

${ }^{a}$ Sen: sensitivity is the capacity for detecting CXCR4-using viruses, calculated by the number of concordant X4/R5X4 results divided by the number of viruses phenotyped as R5X4/X4.

${ }^{\text {b}}$ Spe: specificity is the capacity for detecting exclusive CCR5-using viruses, calculated by the number of concordant R5 results divided by the number of viruses phenotyped as R5.

$\kappa$ : kappa coefficient.

shown in Figure $1 b[24,25]$. One virus had an arginine (R) at position 25 with a net charge at +6 and had an R5X4 phenotype (Figure 1a and Table 2). Eleven viruses had no "R" or "K" at positions 11 or 25 , net charges < +5 , and $\mathrm{R} 5$ phenotypes. Five viruses each had a lysine (K) at position 25 with a net charge $<+5$, four of which had an R5 phenotype and only one of which had an R5X4 phenotype. Two viruses each had a $\mathrm{K}$ at position 25 with a net charge of +5 and were phenotyped as R5. We studied different clones from the HIV-1 quasispecies of three patients harboring R5 virus populations on bulk phenotypic analysis but predicted to be $\mathrm{X} 4$ by the bulk genotypic analysis when using the algorithms built for subtype B viruses. All the clones successfully phenotyped were $\mathrm{R} 5$ and had a lysine (K) at position 25 with net charges comprised between +1 and +4 (Figure 2 ). Thus, HIV-1 subtype D viruses frequently have a lysine at position 25 and viruses use exclusively CCR 5 for entry when this amino acid is associated with a V3 net charge $\leq+5$.

Table 2 Genotypic determinants predicting coreceptor use by HIV-1 subtype $D$ viruses

\begin{tabular}{|c|c|c|c|}
\hline \multirow[b]{2}{*}{ 11/25 Amino Acids } & \multirow[b]{2}{*}{ Net charge } & \multicolumn{2}{|c|}{$\begin{array}{l}\text { No. of Bulk Sequences with } \\
\text { the Indicated Phenotype } \\
\text { (TTT) }\end{array}$} \\
\hline & & R5 & $\mathrm{R} 5 \mathrm{X} 4 / \mathrm{X} 4$ \\
\hline \multirow[t]{2}{*}{ "R" or "K" at 11} & $<+5$ & 0 & 0 \\
\hline & $\geq+5$ & 0 & $2^{*}$ \\
\hline \multirow[t]{3}{*}{ "K" at 25} & $<+5$ & 4 & 1 \\
\hline & $=+5$ & 2 & 0 \\
\hline & $>+5$ & 0 & 0 \\
\hline \multirow[t]{2}{*}{ "R" at 25} & $<+5$ & 1 & 0 \\
\hline & $\geq+5$ & 1 & $3^{*}$ \\
\hline \multirow[t]{2}{*}{ No "R" or "K" at 11 or 25} & $<+6$ & 14 & 0 \\
\hline & $\geq+6$ & 0 & 0 \\
\hline
\end{tabular}

*The two viruses harboring an arginine at position 11 have also an arginine at position 25 .
We, therefore, designed a genotypic rule based on the $11 / 25$ and net charge rules for determining the tropism of HIV-1 subtype D. One of the following criteria was required for predicting subtype D CXCR4 coreceptor usage: (i) $\mathrm{R}$ or $\mathrm{K}$ at position 11 of V3; (ii) $\mathrm{R}$ at position 25 of V3 and a net charge of $\geq+5$; (iii) a net charge of $\geq+6$. The genotypic and phenotypic approaches using this rule were $92 \%$ concordant (Table 3 ). This subtype D genotypic algorithm was $75 \%$ sensitive and $95 \%$ specific with our data set.

\section{Validation of the subtype $\mathrm{D}$ genotypic algorithm on an independent data set}

The GenBank dataset of subtype D viruses included 25 R5X4/X4 viruses and $42 \mathrm{R} 5$ viruses based on phenotypic assays. We analyzed phylogenetically the GenBank V3 sequences and the $26 \mathrm{~V} 3$ sequences from patients (Figure 3). We predicted the tropism of these viruses with the initially validated combined rule [10], with the geno2pheno tool and with the subtype D genotypic algorithm based on the simple $11 / 25$ and net charge rules (Table 4). The concordance between genotypic and phenotypic determinations was $69 \%$ with the combined rule and $67 \%$ with geno2pheno10. The concordance increased to $85 \%$ using the subtype D genotypic algorithm. The subtype D tool was $68 \%$ sensitive and $95 \%$ specific for detecting CXCR4-using viruses. Geno2pheno10 was the most sensitive tool (96\%) but its specificity was poor $(50 \%)$.

\section{Discussion}

HIV-1 subtype D infections have been associated with rapid disease progression [14-16,18] and a high prevalence of CXCR4-using viruses according to phenotypic assays [19-21]. A genotypic assay for determining subtype D tropism would be useful for investigating the pathogenesis of this subtype and for facilitating the clinical use of CCR5 antagonists. But recent studies indicate that the genotypic algorithms currently used are relatively insensitive for non-B subtypes, although their performance for particular subtypes was not specifically 
determined [9]. We have now analyzed the correlations between phenotypic and genotypic approaches for determining HIV-1 subtype D tropism.

The prevalence of X4 viruses estimated in 26 patients with the TTT phenotypic assay was $15 \%$. The TTT assay has previously been validated on B and non-B subtypes and correlated well with the enhanced sensitive Trofile assay $[3,26]$. The scarcity of CXCR4-using viruses in these patients could be because they were at a different stage of the disease compared to the patients recruited in Uganda and Sudan in previous studies [19-21]. The genotypic determination of HIV-1 tropism with algorithms built for the subtype B were adequately sensitive (75\% with geno2pheno10 and $100 \%$ with the combined $11 / 25$ and net charge rules), but were poorly specific (54\% to 68\%, respectively) for predicting CXCR4 use by subtype D viruses. One previous study of the performance of two genotypic algorithms for determining subtype D tropism reported poor specificity, 74\% for the $11 \mathrm{RK} / 25 \mathrm{~K}$ rule and 53\% for the PSSM algorithm [20].

We therefore analyzed the V3-loop sequences and the corresponding phenotype of these subtype D viruses. We found that the lysine at position 25 is a polymorphic amino acid in HIV-1 subtype D and should not be considered as a determinant of CXCR4 usage for this particular subtype, in the contrary with subtype B viruses. We confirmed this polymorphism at a clonal level on three virus populations phenotyped R5. The V1-V2 env region may also influence the virus tropism [27-29]. A recent study found that analysis of the V2-V3 region

Table 3 Genotypic prediction of HIV-1 tropism by a subtype D specific algorithm compared to the observed phenotype

\begin{tabular}{|c|c|c|c|c|c|c|}
\hline \multirow[b]{2}{*}{ Genotypic tool } & & \multicolumn{2}{|c|}{ TTT } & \multirow[t]{2}{*}{ Concordance } & \multicolumn{2}{|c|}{ Genotypic Prediction } \\
\hline & & R5 & $\mathrm{R} 5 \mathrm{X} 4 / \mathrm{X} 4$ & & $\operatorname{Sen}^{a}$ & Spe $^{b}$ \\
\hline \multirow[t]{2}{*}{ Combined $11 / 25$ and net charge rules for subtype $D$} & R5 & 21 & 1 & $92 \%$ & $75 \%$ & $95 \%$ \\
\hline & $\mathrm{X} 4$ & 1 & 3 & $\kappa=0.70(p<0.001)$ & & \\
\hline
\end{tabular}

Sen: sensitivity for predicting CXCR4-using viruses

${ }^{b}$ Spe: specificity for predicting CXCR4-using viruses

$\kappa$ : kappa coefficient. 


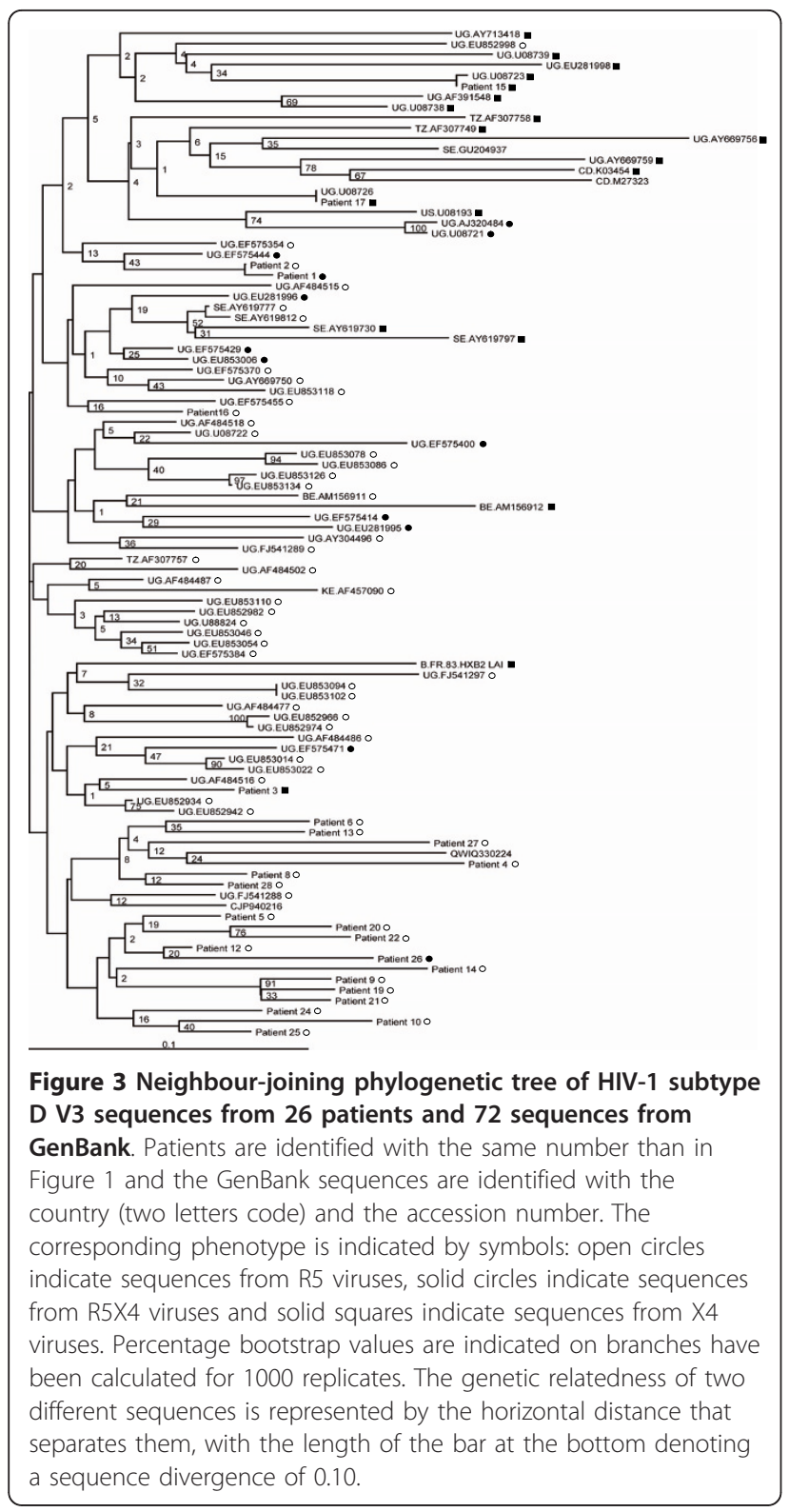

slightly improved the sensitivity for predicting CXCR4 usage compared to analysis of V3 alone [30]. However, we previously analyzed the V1 and V2 regions of subtype $B$ viruses and found no criteria that improved the genotypic prediction [8]. For subtype D viruses, no genotypic determinant has been identified in the V1-V2 region that improves the performance of the genotypic approaches (data not shown). The determinants identified for predicting CXCR4 usage by subtype D viruses were combined in a simple genotypic rule that differed slightly from the combined rule validated for subtype $\mathrm{B}$, $\mathrm{C}$ and CRF02-AG [10-12]. The concordance between the subtype D genotypic rule and the TTT (kappa coefficient: 0.70) was better than that for the subtype B tools (kappa coefficients: 0.15-0.40). The sensitivity of the subtype D genotypic rule (75\%) was similar to that of the subtype B genotypic algorithms, applied to subtype $B$ viruses to determine tropism (69 to 88\%) [10].

One limit of the study was the small number of X4 viruses in our patients (4/26). However, R5 viruses with an $\mathrm{X} 4$ genotype using current algorithms were very informative and analysis of our dataset enabled us to propose a new interpretation rule for HIV-1 subtype D tropism. This new rule was subsequently validated by examination of a GenBank set of 67 subtype D V3 sequences belonging to viruses whose phenotype was known. The best concordance with the phenotype was obtained with the subtype D combined rule (sensitivity $68 \%$, specificity $95 \%$ ), giving a good agreement with the phenotypic assay (kappa coefficient of 0.63). This specific genotypic algorithm predicted HIV-1 tropism better than did the MT2 or Trofile phenotypic assays (data not shown). The specificity of the V3 genotype is important for not excluding patients eligible for antiretroviral treatment based on a CCR5 antagonist and for epidemiological and pathophysiological studies. The specificity of the V3 genotype is also crucial for accurate characterization of HIV-1 quasispecies by ultra-deep

Table 4 Comparison of genotypic prediction of HIV tropism and the observed phenotype on a GenBank data set of HIV-1 subtype D viruses

\begin{tabular}{|c|c|c|c|c|c|c|}
\hline \multirow[b]{2}{*}{ Genotypic tool } & & \multicolumn{2}{|c|}{ Phenotype } & \multirow[t]{2}{*}{ Concordance } & \multicolumn{2}{|c|}{ Genotypic Prediction } \\
\hline & & R5 & $\mathrm{R} 5 \mathrm{X} 4 / \mathrm{X} 4$ & & $\operatorname{Sen}^{\mathrm{a}}$ & $\mathrm{Spe}^{\mathrm{b}}$ \\
\hline \multirow[t]{2}{*}{ Geno2pheno10 } & R5 & 21 & 1 & $67 \%$ & $96 \%$ & $50 \%$ \\
\hline & $\mathrm{X} 4$ & 21 & 24 & $\kappa=0.40(p<0.001)$ & & \\
\hline \multirow[t]{2}{*}{ Combined $11 / 25$ and net charge rules } & R5 & 26 & 5 & $69 \%$ & $80 \%$ & $62 \%$ \\
\hline & $\mathrm{X} 4$ & 16 & 20 & $\kappa=0.38(p<0.001)$ & & \\
\hline \multirow[t]{2}{*}{ Combined $11 / 25$ and net charge rules for subtype $D$} & R5 & 40 & 8 & $85 \%$ & $68 \%$ & $95 \%$ \\
\hline & $\mathrm{X} 4$ & 2 & 17 & $\kappa=0.63(p<0.0001)$ & & \\
\hline
\end{tabular}

\footnotetext{
${ }^{\mathrm{a}}$ Sen: sensitivity for predicting CXCR4-using viruses

${ }^{b}$ Spe: specificity for predicting CXCR4-using viruses

$\kappa$ : kappa coefficient.
} 
pyrosequencing, which improves the sensitivity for detecting CXCR4-using viruses.

\section{Conclusion}

The combined rule with criteria from the 11/25 and net charge rules modified for subtype D HIV-1 performed well for predicting the tropism of this particular subtype. Simple genotypic methods could make it easier to determine the impact of virus tropism on disease progression and to facilitate the clinical use of CCR5 antagonists. Further studies are now needed to optimize the various genotypic algorithms for predicting the tropism of other HIV-1 non-B subtypes.

\section{Acknowledgements and Funding}

The English text was edited by Dr Owen Parkes.

Financial support for this work was provided by INSERM U1043.

\section{Author details}

${ }^{1}$ INSERM, U1043, Toulouse, F-31300 France. ${ }^{2}$ Université Toulouse III PaulSabatier, Faculté de Médecine Toulouse-Purpan, Toulouse, F-31300 France. ${ }^{3} \mathrm{CHU}$ de Toulouse, Hôpital Purpan, Laboratoire de Virologie, Toulouse, F31300 France. ${ }^{4} \mathrm{CHU}$ de Toulouse, Hôpital Purpan, Service des Maladies Infectieuses et Tropicales, Toulouse, F-31300 France. ${ }^{5}$ Université Paris Descartes, EA 3620, AP-HP, laboratoire de Virologie, Hôpital Necker-Enfants Malades, Paris, France.

\section{Authors' contributions}

SR, PD and JI assisted with manuscript writing; MLC, BM and PM assisted with patients' care and data acquisition; MC, SE and PB assisted with laboratory assays; KSS assisted with methodological approach; Jl and PD assisted with research group leading. All authors read and approved the final manuscript.

\section{Competing interests}

The authors declare that they have no competing interests.

Received: 17 March 2011 Accepted: 13 July 2011

Published: 13 July 2011

\section{References}

1. Berger EA, Murphy PM, Farber JM: Chemokine receptors as HIV-1 coreceptors: roles in viral entry, tropism, and disease. Annu Rev Immunol 1999, 17:657-700.

2. Dorr P, Westby M, Dobbs S, Griffin P, Irvine B, Macartney M, Mori J, Rickett G, Smith-Burchnell C, Napier C, et al: Maraviroc (UK-427,857), a potent, orally bioavailable, and selective small-molecule inhibitor of chemokine receptor CCR5 with broad-spectrum anti-human immunodeficiency virus type 1 activity. Antimicrob Agents Chemother 2005, 49:4721-4732.

3. Raymond S, Delobel P, Mavigner M, Cazabat M, Souyris C, Encinas S, Bruel P, Sandres-Saune K, Marchou B, Massip P, Izopet J: Development and performance of a new recombinant virus phenotypic entry assay to determine HIV-1 coreceptor usage. J Clin Virol 2010, 47:126-130.

4. Trouplin V, Salvatori F, Cappello F, Obry V, Brelot A, Heveker N, Alizon M, Scarlatti G, Clavel F, Mammano F: Determination of coreceptor usage of human immunodeficiency virus type 1 from patient plasma samples by using a recombinant phenotypic assay. J Virol 2001, 75:251-259.

5. Whitcomb JM, Huang W, Fransen S, Limoli K, Toma J, Wrin T, Chappey C, Kiss LD, Paxinos EE, Petropoulos CJ: Development and characterization of a novel single-cycle recombinant-virus assay to determine human immunodeficiency virus type 1 coreceptor tropism. Antimicrob Agents Chemother 2007, 51:566-575.

6. Recordon-Pinson $P$, Soulie $C$, Flandre $P$, Descamps D, Lazrek $M$, Charpentier C, Montes B, Trabaud MA, Cottalorda J, Schneider V, et al:
Evaluation of the genotypic prediction of HIV-1 coreceptor use versus a phenotypic assay and correlation with the virological response to maraviroc: the ANRS GenoTropism study. Antimicrob Agents Chemother 2010, 54:3335-3340.

7. Seclen E, Garrido C, Gonzalez Mdel M, Gonzalez-Lahoz J, de Mendoza C, Soriano V, Poveda E: High sensitivity of specific genotypic tools for detection of X4 variants in antiretroviral-experienced patients suitable to be treated with CCR5 antagonists. J Antimicrob Chemother 2010, 65:1486-1492.

8. Delobel P, Nugeyre MT, Cazabat M, Pasquier C, Marchou B, Massip P, BarreSinoussi F, Israel N, Izopet J: Population-based sequencing of the V3 region of env for predicting the coreceptor usage of human immunodeficiency virus type 1 quasispecies. J Clin Microbiol 2007, 45:1572-1580.

9. Garrido C, Roulet V, Chueca N, Poveda E, Aguilera A, Skrabal K, Zahonero N, Carlos S, Garcia F, Faudon JL, et al: Evaluation of eight different bioinformatics tools to predict viral tropism in different human immunodeficiency virus type 1 subtypes. J Clin Microbiol 2008, 46:887-891.

10. Raymond S, Delobel P, Mavigner M, Cazabat M, Souyris C, Sandres-Saune K, Cuzin L, Marchou B, Massip P, Izopet J: Correlation between genotypic predictions based on $\mathrm{V} 3$ sequences and phenotypic determination of HIV-1 tropism. Aids 2008, 22:F11-16.

11. Raymond S, Delobel P, Mavigner M, Cazabat M, Souyris C, Encinas S, Sandres-Saune K, Pasquier C, Marchou B, Massip P, Izopet J: Genotypic prediction of human immunodeficiency virus type 1 CRF02-AG tropism. J Clin Microbiol 2009, 47:2292-2294.

12. Raymond S, Delobel P, Mavigner M, Ferradini L, Cazabat M, Souyris C, Sandres-Saune K, Pasquier C, Marchou B, Massip P, Izopet J: Prediction of HIV type 1 subtype $C$ tropism by genotypic algorithms built from subtype B viruses. J Acquir Immune Defic Syndr 2010, 53:167-175.

13. Taylor BS, Hammer SM: The challenge of HIV-1 subtype diversity. N Eng/ J Med 2008, 359:1965-1966.

14. Baeten JM, Chohan B, Lavreys L, Chohan V, McClelland RS, Certain L, Mandaliya K, Jaoko W, Overbaugh J: HIV-1 subtype D infection is associated with faster disease progression than subtype $A$ in spite of similar plasma HIV-1 loads. J Infect Dis 2007, 195:1177-1180.

15. Easterbrook PJ, Smith M, Mullen J, O'Shea S, Chrystie I, de Ruiter A, Tatt ID, Geretti AM, Zuckerman M: Impact of HIV-1 viral subtype on disease progression and response to antiretroviral therapy. J Int AIDS Soc 2010, 13:4.

16. Kaleebu P, French N, Mahe C, Yirrell D, Watera C, Lyagoba F, Nakiyingi J, Rutebemberwa A, Morgan D, Weber J, et al: Effect of human immunodeficiency virus (HIV) type 1 envelope subtypes $A$ and $D$ on disease progression in a large cohort of HIV-1-positive persons in Uganda. J Infect Dis 2002, 185:1244-1250.

17. Kiwanuka N, Robb M, Laeyendecker O, Kigozi G, Wabwire-Mangen F, Makumbi FE, Nalugoda F, Kagaayi J, Eller M, Eller LA, et al: HIV-1 viral subtype differences in the rate of CD4+ T-cell decline among HIV seroincident antiretroviral naive persons in Rakai district, Uganda. $J$ Acquir Immune Defic Syndr 2010, 54:180-184.

18. Vasan A, Renjifo B, Hertzmark E, Chaplin B, Msamanga G, Essex M, Fawzi W, Hunter D: Different rates of disease progression of HIV type 1 infection in Tanzania based on infecting subtype. Clin Infect Dis 2006, 42:843-852.

19. Church JD, Huang W, Mwatha A, Toma J, Stawiski E, Donnell D, Guay LA, Mmiro F, Musoke P, Jackson JB, et al: HIV-1 tropism and survival in vertically infected Ugandan infants. J Infect Dis 2008, 197:1382-1388.

20. Huang W, Eshleman SH, Toma J, Fransen S, Stawiski E, Paxinos EE, Whitcomb JM, Young AM, Donnell D, Mmiro F, et al: Coreceptor tropism in human immunodeficiency virus type 1 subtype $D$ : high prevalence of CXCR4 tropism and heterogeneous composition of viral populations. J Virol 2007, 81:7885-7893.

21. Kaleebu P, Nankya IL, Yirrell DL, Shafer LA, Kyosiimire-Lugemwa J, Lule DB, Morgan D, Beddows S, Weber J, Whitworth JA: Relation between chemokine receptor use, disease stage, and HIV-1 subtypes A and D: results from a rural Ugandan cohort. J Acquir Immune Defic Syndr 2007, 45:28-33.

22. De Wolf F, Hogervorst E, Goudsmit J, Fenyo EM, Rubsamen-Waigmann H, Holmes H, Galvao-Castro B, Karita E, Wasi C, Sempala SD, et al: Syncytiuminducing and non-syncytium-inducing capacity of human immunodeficiency virus type 1 subtypes other than B: phenotypic and 
genotypic characteristics. WHO Network for HIV Isolation and Characterization. AIDS Res Hum Retroviruses 1994, 10:1387-1400.

23. Zhong P, Peeters M, Janssens W, Fransen $K$, Heyndrickx L, Vanham G, Willems B, Piot P, van der Groen G: Correlation between genetic and biological properties of biologically cloned HIV type 1 viruses representing subtypes A, B, and D. AIDS Res Hum Retroviruses 1995, 11:239-248.

24. De Jong JJ, De Ronde A, Keulen W, Tersmette M, Goudsmit J: Minimal requirements for the human immunodeficiency virus type $1 \mathrm{~V} 3$ domain to support the syncytium-inducing phenotype: analysis by single amino acid substitution. J Virol 1992, 66:6777-6780.

25. Fouchier RA, Groenink M, Kootstra NA, Tersmette M, Huisman HG, Miedema F, Schuitemaker H: Phenotype-associated sequence variation in the third variable domain of the human immunodeficiency virus type 1 gp120 molecule. J Virol 1992, 66:3183-3187.

26. Saliou A, Delobel P, Dubois M, Nicot F, Raymond S, Calvez V, Masquelier B, Izopet J: Concordance between Two Phenotypic Assays and Ultradeep Pyrosequencing for Determining HIV-1 Tropism. Antimicrob Agents Chemother 2011, 55:2831-2836.

27. Carrillo A, Ratner L: Cooperative effects of the human immunodeficiency virus type 1 envelope variable loops $\mathrm{V} 1$ and $\mathrm{V} 3$ in mediating infectivity for T cells. J Virol 1996, 70:1310-1316.

28. Masciotra S, Owen SM, Rudolph D, Yang C, Wang B, Saksena N, Spira T, Dhawan S, Lal RB: Temporal relationship between V1V2 variation, macrophage replication, and coreceptor adaptation during HIV-1 disease progression. AIDS 2002, 16:1887-1898.

29. Groenink M, Andeweg AC, Fouchier RA, Broersen S, van der Jagt RC, Schuitemaker H, de Goede RE, Bosch ML, Huisman HG, Tersmette M: Phenotype-associated env gene variation among eight related human immunodeficiency virus type 1 clones: evidence for in vivo recombination and determinants of cytotropism outside the V3 domain. J Virol 1992, 66:6175-6180.

30. Thielen A, Sichtig N, Kaiser R, Lam J, Harrigan PR, Lengauer T: Improved prediction of HIV-1 coreceptor usage with sequence information from the second hypervariable loop of gp120. J Infect Dis 2010, 202:1435-1443.

doi:10.1186/1742-4690-8-56

Cite this article as: Raymond et al: Genotypic prediction of HIV-1 subtype D tropism. Retrovirology 2011 8:56.

\section{Submit your next manuscript to BioMed Central and take full advantage of:}

- Convenient online submission

- Thorough peer review

- No space constraints or color figure charges

- Immediate publication on acceptance

- Inclusion in PubMed, CAS, Scopus and Google Scholar

- Research which is freely available for redistribution

Submit your manuscript at www.biomedcentral.com/submit 